\title{
TABARA: UN LARGO Y COMPLEJO PROCESO DE FORMACION SEÑORIAL EN TIERRAS DE ZAMORA
}

\author{
Alfonso Franco Silva \\ Universidad de Córdoba \\ Isabel Beceiro \\ Universidad de Valladolid
}

\section{INTRODUCCION}

El linaje de los Mendoza y la organización de sus extensos territorios en Castilla constituye uno de los objetos fundamentales de nuestra investigación en los últimos años (1). Entre los diferentes señorios que, a través de enlaces matrimoniales, se incorporaron al ducado del infantado se hallan algunos pequeños estados territoriales que pasaron al tronco central de los Mendoza como herencia de la casa de Pastrana. Uno de ellos, el marquesado de Tábara, constituye el objeto de estas páginas. A pesar de que el título de marqués de Tábara les fue concedido en el siglo XVI a una rama menor de dos grandes linajes, los orígenes del señorio propiamente dicho arrancan de muy atrás, concretamente del siglo XV. EI proceso de formación del marquesado de Tábara resultó ser ciertamente complicado, y no se verá consolidado hasta los comienzos del siglo XVI. A mediados del siglo $X V$, dos grandes linajes castellanos, los Pimentel, condes de Benavente, y los Enríquez, almirantes de Castilla, formaron dos mayorazgos para dos segundones de sus respectivas familias. A pesar de los intentos de los titulares de estos dos grandes linajes para recuperar posteriormente los territorios desgajados de sus dominios (2), la casa de Tábara alcanza una situación estable a mediados del XVI y conseguirá pervivir durante los siglos XVII y XVIII. El objetivo principal de este trabajo consiste en mostrar la incorporación de las villas y lugares, que luego formarán el marquesado, a los grandes señorios, la formación y unificación de los tres mayorazgos y la consolidación definitiva del marquesado de Tábara. 


\section{EL MAYORAZGO DE DON PEDRO PIMENTEL}

Esencialmente arranca del reparto territorial dispuesto en el testamento de don Alfonso Pimentel, tercer conde de Benavente, en 1455 (3). En este testamento divide entre sus hijos varones sus posesiones, amputando una serie de ellas del mayorazgo que habia fundado su padre. Sin embargo, fue parcialmente modificado en una época que se puede suponer inmediatamente anterior a la muerte del conde, el 21 de febrero de 1461. Este segundo testamento no se ha conservado, pero se puede reconstruir parcialmente por referencias contenidas en documentos posteriores. La parte de su hijo don Pedro se configura esencialmente con los lugares de Pobladura del Valle, Comonte, la villa de Gondoncillo con su aldea de Retuerta, la de Alija y sus lugares de La Nora y El Burgo, el portazgo de la aldea de Puente de Vizana, anejo al término de Alija, y 60.000 maravedis de juro en Astorga (4), aunque en realidad, Alija y su término pertenecian propiamente a la condesa.

Este señorío se amplía con el mayorazgo fundado para don Pedro por la condesa viuda doña María de Quiñones. En él se ratifica el legado de don Alfonso y se añaden algunas localidades nuevas. Está contenido en su testamento del 20 de febrero de 1477 y comprende Gordoncillo y Alija, con sus respectivos términos, Pobladura del Valle, Comonte, y además Puente de Vizana y Ginestacio (5).

Todo ello estaba situado en las actuales provincias de Zamora y León y procedia de los condados de Luna y Benavente. Ginestacio constituia la dote destinada a doña María por su padre, el conde de Luna (6). Alija y sus aldeas habían sido donados por Juan II a la citada condesa de Benavente en 1446, en señal de la reconciliación entre el rey y la nobleza a raíz de la batalla de Olmedo.(7). Por último, varias villas y lugares habian sido compradas por el antecesor de don Alfonso Pimentel. Vamos a tratar de seguir el destino de cada una de estas localidades hasta el momento en que se integran en el mayorazgo de don Pedro.

\subsection{Puente de Vizana o de Bazán}

En 1469, doña María de Quiñones compró a Luis Ponce, hijo de Alvar Ponce, la cuarta parte que le pertenecía en Puente de Vizana (8). Luis Ponce, en un documento posterior, ratificó la venta y se comprometió a no hacer ningún tipo de reclamaciones a los herederos de doña Maria. A principios del siglo XVI los Benavente traspasan el lugar a la Casa de Tábara a cambio de Gordoncillo, sin que podamos conocer con claridad cómo lo adquirieron previamente (9).

\subsection{Ginestacio}

El lugar de Ginestacio, próximo a la villa de Quintana del Marco, pertenecía a los dominios del linaje Quiñones, hasta que el 24 de noviem- 
bre de 1440 Diego Fernández de Quiñones, Merino Mayor de Asturias, se la cedió como dote a su hija María de Quiñones (10). Ginestacio se valoró en ese año en 210.000 maravedís y formaria parte del total de 1.100.000 maravedís, que recibió el conde de Benavente al casar con doña Maria. Dos años más tarde, el 3 de febrero de 1442, los condes de Luna, Diego Fernández de Quiñones y María de Toledo, confirmaban en su testamento, otorgando en León, la posesión de Ginestacio a su hija la condesa de Benavente (11).

\subsection{Gordoncillo}

Esta villa pertenecía al linaje de los Prado, descendientes de Martín Díaz de Prado a quien don Alfonso VII había concedido la iglesia de Velerda, en el territorio de Caso, junto al asturiano río Nalón (12). Unos años antes, en Toledo, el 18 de septiembre de 1142, Alfonso VIl y su mujer doña Berenguela habian donado a Martín Díaz la villa de Albires y su valle, en el reino de León, junto a Mayorga. En 1392 un descendiente suyo, también llamado Martín Díaz, casa con Inés Alvarez, hija del señor de la villa leonesa de Valderas, Alvar Pérez Osorio. Doña Inés recibe entonces como dote Gordoncillo y su aldea de Retuerta, que Alvar Pérez desgaja del alfoz de Valderas (13).

El 26 de mayo de 1434, su hijo Rodrigo de Prado vende al segundo conde de Benavente, y antecesor de don Alfonso Pimentel, estas dos localidades. El motivo de la venta es la obligación de entregar mil florines como arras para su boda con María de Vega (14). A cambio de Gordoncillo y Retuerta, obtiene 20.000 maravedís de juro de heredad en ciertas rentas de la ciudad de Zamora y 3.000 florines de oro, que ascendieron en total a unos 180.000 maravedis (15). Después de su incorporación al mayorazgo de don Pedro Pimentel, los condes intentan reiteradamente efectuar un trueque con don Pedro para recuperar estas posesiones. El primero de estos intentos se produce en 1484: es un concierto entre el cuarto conde de Benavente y su hermano por el cual el primero dará a don Pedro la merindad de Valladolid, en el caso de que le sea concedida por los Reyes Católicos en juro de heredad, y recibirá a cambio Gordoncillo y su aldea (16). Evidentemente, este acuerdo no se llevó a la práctica, pues durante todo el siglo XV Gondoncillo y Retuerta continuaron en manos de don Pedro, pero a principios del XVI vuelven al condado de Benavente, cuyo titular entrega Puente de Bayzan y 350.000 maravedís (17). No se sabe en qué año se efectuó este trueque, pero tuvo que ser en 1500 , porque al año siguiente ya figuran las rentas de Gordoncillo adscritas al condado (18).

\subsection{Pobladura del Valle}

Este lugar formaba parte de los dominios de Men Rodríguez de Benavides, señor de Santisteban del Puerto en el reino de Jaén, en que lo 
vendió al segundo conde de Benavente junto con el lugar de Cebrones del Río (19). Don Rodrigo Alfonso Pimentel firmó el contrato de compraventa el 22 de mayo de ese año y entregó a Benavides 5.280 maravedís de juro de heredad, que serian situados en las alcabalas de las carnes vivas y muertas de Baeza, Ubeda y Santisteban del Puerto (20). Men Rodríguez de Benavides lo ratificó en Ibros, lugar de Baeza, el 23 de julio de 1430.

\subsection{Alija}

En 1369 Enrique ll de Trastamara concedió esta villa a su vasallo Juan Rodríguez de Neira (21). Un año más tarde, el 26 de marzo de 1370, el monarca comunicaba a su canciller mayor que había hecho donación de Alija a Rodríguez de Neira, así como también de todos los bienes que poseía Pedro García de Castro en San Millán, cerca de Valencia de Campos. Juan I confirmó ambos privilegios en Burgos el 30 de agosto de 1379 , reservándose para la Corona las rentas reales de la villa. Unos años después, el 5 de junio de 1385, el monarca volvió a confirmar la donación a Juan Rodríguez de Neira, y más tarde, el 20 de febrero de 1392, Enrique III confirmaba a su vez la merced de Alija a Gómez Yáñez de Neira, hijo del anterior (22).

A Gómez Yáñez le sucedió como señor de Alija su hijo Pedro de Meira que murió sin sucesión, retornando la villa a la Corona. El 23 de abril de 1446 Juan II donaba Alija y sus lugares a la condesa de Benavente. Esta concesión se enmarca en la política del monarca en aquellos momentos de atraerse a los Pimentel y separarlos del resto de la coalición nobiliar y partidaria de los infantes de Aragón (23). Unos años más tarde, en 1477, doña María de Quiñones cedía Alija a su hijo Pedro Pimentel, tras la renuncia a la posesión de la villa por parte del primogénito, Rodrigo Alfonso Pimentel.

\subsection{Comonte}

Hasta 1434 pertenecía a Juan de Nera o Neira, probablemente hermano del que fue señor de Alija, Pedro de Neira. En esta fecha vende el lugar al segundo conde de Benavente, por 150.000 maravedís. El motivo de la venta son las deudas de Juan de Neira con Gutierre Ponce, regidor y representante del concejo de Benavente. En 1433, y por el mismo motivo, habia salido a pública subasta su localidad de Manganeses, después de haberlo empeñado dos años antes. Pero esta vez fue el concejo de Benavente quien realizó esta adquisición (24).

\section{EL MAYORAZGO DEL LINAJE ALMANSA}

El linaje Almansa aparece en la escena politica del reino de Castilla en la época de los Trastámaras. Efectivamente, el 8 de septiembre de 1371 
Enrique II premiaba los servicios de su vasallo Gómez Pérez de Valderrábano con la donación de una serie de lugares: Alcañices, Tábara, Mombuey y Ayóo (hoy Ayóo de Vidriales) (25). Las villas y lugares mencionados pertenecían a la tierra de Zamora. Gómez Pérez no era, sin embargo, un advenedizo, pues los informes del Archivo de Osuna le hacen descender de don Arias Díaz de las Asturias, primer señor de Valderrábano, y de su esposa Aldonza González Froilaz, señora de Alcañices (26). La donación que le hace Enrique II a Gómez Pérez fue confirmada por Juan I en Burgos el 12 de agosto de 1379. El monarca menciona en su carta de confirmación los principales motivos de esta merced: Ios numerosos servicios que Gómez Pérez había prestado a su padre y a él mismo (27). Juan I se reservaba para la Corona las alcabalas, pedidos, moneda forera y minas de oro y plata de esas villas, con la expresa obligación de que Gómez Pérez le diese posada cuando las visitase acompañado de su esposa y de su madre.

Unos años más tarde Enrique III, en un documento fechado en Madrid el 15 de diciembre de 1393, confirmaba la donación de esas villas a Luis y Ramiro de Almansa, hijos y herederos de Gómez Pérez y de su esposa Juana Gómez de Cifuentes (28).

No volvemos a tener noticias de este linaje hasta el año 1460 , en que era señor de estas villas don Diego de Almansa, biznieto de Gómez Pérez. El 18 de enero de 1465 don Diego, ante la falta de hijos varones, formó dos mayorazgos para sus hijas Francisca y Constanza, casadas respectivamente con don Pedro Pimentel y con Juan Enriquez, señor de Belber y Sobreros y primer conde de Alba de Aliste (29). La hija primogénita, Francisca de Almansa, recibiría las villas de Almansa, Alcañices y Tábara. A doña Constanza le correspondió el lugar de Villabel de Ayóo, las casas de Zamora, la heredad y rentas de la localidad de Moreruela y 5.000 maravedis de juro sobre las alcabalas de los lugares de la Mediana.

Doña Francisca de Almansa, esposa de Pedro Pimentel, falleció pronto, dejando como heredero a su hijo único llamado Pedro, que poco después moría también, siendo aún menor de edad (30). La herencia de los Almansa pasaba, pues, a la única heredera viva, doña Constanza, mujer del conde de Alba de Aliste. Sin embargo, don Pedro Pimentel abrigaba planes para recuperar en su favor el patrimonio de su esposa $e$ hijo. Para conseguir su objetivo, Pimentel manifestó que las villas de Tábara, Almansa y Alcañices le pertenecían como único heredero vivo de su hijo Pedro. Poco después y para neutralizar las pretensiones del conde de Alba de Aliste, solicitaba en matrimonio a la hija de este último, doña Inés Enriquez de Almansa. Finalmente, se dirigía a los Reyes Católicos invocando los numerosos servicios que sus antepasados habian prestado a la Corona. Los monarcas, para no enemistarse con un linaje tan poderoso como el de los Pimentel, le despacharon un privilegio el 28 de enero de 1487 por el que le concedian las villas de Almansa y Tábara y le daban licencia para formar un mayorazgo (31).

Sin embargo, pronto surgieron problemas. El 21 de agosto de 1489 , don Francisco Enriquez de Almansa, hijo del conde de Alba de Aliste, presentó 
en la Chancillería de Valladolid una demanda contra Pedro Pimentel. Don Francisco exigía la devolución del patrimonio de su tía Francisca de Almansa. La Chancillería, adoptando una solución salomónica, procedió a dividir las villas entre los dos herederos: don Francisco recibía Almansa y Alcañices y don Pedro Pimentel la villa de Tábara (32).

El resultado del pleito no satisfizo las ambiciones de don Pedro Pimentel, pues juzgaba que le era claramente desfavorable. En consecuencia, elevó una súplica a Fernando el Católico. La sentencia del monarca, pronunciada en Valladolid el 12 de marzo de 1510, no hacía sino confirmar la de la Chancillería y el patrimonio quedó, por tanto, dividido (33).

Por otra parte, Almansa fue objeto de nuevos acuerdos entre don Pedro Pimentel y el conde de Benavente. El 30 de noviembre de 1470 don Pedro se compromete a entregar Almansa y, a cambio, su hermano don Rodrigo le dará villas, rentas y vasallos por el mismo valor (34). Y, provisionalmente, el conde da en tenencia a don Pedro la villa de Villafáfila, que no pertenecía a su señorío sino a la Orden de Santiago, pero que tenía en arriendo del comendador de Castrotorafe. El acuerdo funcionó en un principio y más o menos parcialmente. Asi, en 1493 el conde disfruta de las alcabalas de Almansa al igual que de las de sus propios dominios y pasa a su hermano las rentas procedentes del arriendo de la villa (35). En cambio, en 1499 parece haberse abandonado esta transacción, quizás porque se ha anulado también el arrendamiento de Villafáfila (36).

En cuanto al mayorazgo de los bienes de don Pedro, fue fundado por este señor y su esposa Inés Enriquez el 9 de agosto de 1497. El heredero sería su hijo don Bernardino Pimentel. Los bienes que se enumeran en este mayorazgo son los siguientes (37):

- La villa de Almansa con su fortaleza, que poco después les sería arrebatada por el conde de Alba de Aliste.

- La villa de Tábara con sus lugares y la tierra de Orcellón y las aceñas de Misleo y Quintos.

- La villa de Alija con sus lugares de La Nora y El Burgo, las posesiones en Puente de Vizana, Ginestacio y Comonte.

- La villa de Gondoncillo y su tierra. Muy pronto sería cambiada por el resto de Puente de Vizana.

- Los vasallos que tenían en Pobladura del Valle.

- 60.000 maravedís de juro en Astorga y la dehesa y término de Carpurias y Ribaroya.

\section{EL MAYORAZGO DEL LINAJE ENRIQUEZ}

En 1473, el almirante don Fadrique Enriquez, con licencia otorgada por Juan Il el 20 de octubre de 1440, procedía a formar cuatro mayorazgos para sus hijos (38). El primogénito, Alonso Enríquez, heredaría el título de Almirante de Castilla y las villas más importantes del linaje: Medina de 
Rioseco, Torrelobatón, Villabrágima y otras. Su hijo segundo, don Pedro Enríquez, Adelantado de Andalucía, casado con la heredera del linaje andaluz de los Ribera, recibía la villa de Tarifa. El tercer hijo, Enrique Enriquez, heredaba las villas de Villada y Villavicencio. Finalmente, el cuarto hijo, Francisco, recibia la villa de Vega de Río Ponce, que años más tarde volvería al tronco principal del linaje porque este último hijo no tuvo descendencia.

De esta herencia sólo nos interesa considerar aqui la que correspondió al tercer hijo, don Enrique Enríquez, señor de Villada y Vallavicencio. Casado más tarde con doña María de Luna, don Enrique no tuvo de ella hijos varones, y como su padre había prohibido en las cláusulas del mayorazgo que éste pudiera transmitirse a las hembras, ambas villas, por tanto, debian retornar a su muerte al linaje primogénito. Don Enrique, para evitar la desaparición de su linaje, se vio obligado a recurrir a sus sobrinos los Reyes Católicos (39). Los monarcas, para complacerle, anularon la cláusula testamentaria de su padre, una vez que el Almirante Alonso Enríquez, en presencia de Isabel y Fernando, y bajo la fórmula feudal del juramento, dio su aprobación a que el mayorazgo de su hermano fuese heredado por una de sus hijas (40). Las relaciones familiares de los Enríquez con Fernando el Católico dieron sus frutos. Los Reyes procedieron a dar facultad y licencia en 1493 y 1495 a don Enrique Enríquez para que formase su propio mayorazgo.

Una vez conseguidos sus propósitos, don Enrique y su esposa fundaron un mayorazgo en Medina del Campo, el 10 de abril de 1504 (41). Su hija Teresa, esposa de Enrique Enriquez de Guzmán, heredaría las villas de Villada, Villavicencio de los Caballeros, el lugar de San Juan de Grajera con Hermita - que después se despobló-, el término de Villamuza y las villas de Riaño, Salio y La Puerta. Según las disposiciones de sus padres, doña Teresa no podía enajenar estas villas ni tampoco imponer tributo alguno sobre ellas. Don Enrique organizaba además la sucesión del mayorazgo de la siguiente manera: si faltaban los hijos varones de doña Teresa heredaría el patrimonio su segunda hija, Elvira Enríquez, casada con el marqués de Priego, a quien le sucedería su hijo segundo. Si Elvira fallecía sin descendencia, el mayorazgo pasaría a su tercera hija, Francisca, esposa del marqués de Denia. Si ésta moría también sin sucesión, los bienes serían heredados por su cuarta hija, María, casada con el duque de Gandia. Finalmente, don Enrique establecia que quien heredase el mayorazgo por él constituido, llevaria el apellido y armas del linaje Enríquez (42). Tres meses más tarde, el 20 de julio de 1504, los Reyes Católicos confirmaron el mayorazgo en Medina del Campo.

Unos años más tarde, tras la muerte de don Enrique Enríquez, heredó el mayorazgo su hija Teresa, que había contraído matrimonio con Enrique Enríquez de Guzmán, conde de Alba de Aliste (43). De esta manera, el patrimonio del linaje Enríquez pasó a formar parte de los dominios del condado de Alba de Aliste cuando el hijo primogénito de este matrimonio, Diego Enríquez de Guzmán, heredó los señorios de sus padres. A media- 
dos del siglo XVI contrae matrimonio Teresa, segunda hija de don Diego Enríquez, con don Pedro Pimentel, segundo marqués de Tábara. Con este enlace, los tres mayorazgos - Pimentel, Almansa y Enríquez- pasaban a formar el patrimonio de un único linaje, el de los marqueses de Tábara (44).

El señorio que aportaban los Enríquez al marquesado de Tábara, estaba formado por cuatro villas y dos lugares. Las villas eran Villada, Villavicencio de los Caballeros, Riaño y Salio y los lugares se denominaban La Puerta y el despoblado de Villamuza. No disponemos de información alguna sobre Riaño, Salio, el término de Villamuza y La Puerta y, por tanto, solamente nos detendremos a considerar la historia de Villada y Villavicencio hasta el momento en que se integraron en los dominios del almirante de Castilla.

\subsection{Villada}

Villada era un lugar de behetría que formaba parte en el siglo XIV de la merindad de Carrión. En el Becerro de las Behetrias, de 1352, se describe la villa como una localidad en la que se ha introducido el señorio compartido de varias personas e instituciones. Se trata del monasterio de Sahagún y, por otra parte, de varios señores laicos: Gonzalo Núñez, Nuño Núñez de Aza, los hijos de Fernando Alvarez de Aza, y Juana Núñez, Urraca Alvarez, Elvira Alvarez, Juana Núñez, Mayor Alvarez, Fernán Alvarez y Juan Núñez de Aza (45). El Becerro enumera las rentas que el rey y los señores de la villa percibian en Villada: los vasallos pagaban al rey servicios y monedas; los solariegos no pagaban la fonsadera, excepto los vasallos pertenecientes al abad de Sahagún. Estos últimos sí lo hacían, pero no pechaban con el yantar ni con la martiniega. Los demás pagaban cada uno tres maravedís en concepto de martiniega por la casa en que vivian. Se hallaban, además, obligados a hacer una serna cada mes y a dar el "cuarto" de la cántara de vino. Por su parte, los vasallos de Sahagún entregaban al abad nueve dineros por la casa en que habitaban, además de realizar una serna obligatoria cada mes.

El 15 de agosto de 1373, Gonzalo Núñez de Guzmán, maestre de la orden de Calatrava, e hijo de Ramiro Froilaz de Guzmán, señor de Belver, y de doña María González de Aza, señora de una parte de Villada, concedía a su primo Pero Núñez de Guzmán, los lugares de Alcozar y Villamizar y parte de Villada (46). Gonzalo Núñez de Guzmán había heredado los dos primeros lugares de su abuelo Ramiro Núñez de Guzmán, y se los dejaba a su primo porque su abuelo había prohibido en su testamento que sus bienes pasasen a una mujer o a una institución religiosa (47). Por último, el donante prevenía a su primo Pero Núñez que había hecho donación a su pariente Gonzalo Núñez de Aza de la parte de Villada que él había recibido de su madre. Unos años más tarde, el 22 de abril de 1391, Enrique III confirmaba en Madrid estas disposiciones de Gonzalo Núñez de Guzmán. 
Sin embargo, esta donación del maestre de Calatrava no tuvo, al parecer, efecto, pues la parte que los Aza poseían en Villada no la heredó Pero Núñez de Guzmán, sino Gonzalo Núñez de Aza. Ignoramos las causas que alteraron las disposiciones del maestre, aunque es posible que él mismo rectificase posteriormente la donación a Pero Núñez, pues ya en el documento de 1373 afirma que la habia concedido a Gonzalo Núñez de Aza. Desde luego, no cabe la menor duda de que Villada pasó a poder de Gonzal o Núñez de Aza, como lo demuestran los datos existentes en el Archivo de Osuna (48). Así, en un documento fechado en 1389 , Gonzalo Núñez apareece ya como señor de Villada. Efectivamente, el 8 de mayo de ese año, Gonzalo Núñez compra por 50.000 maravedis a los albaceas de doña Urraca de Aza, esposa de Gómez Gutiérrez, la parte que esta señora poseía en Villada, excepto las tierras que había legado a su sobrina Juana Núñez de Aza (49). Al día siguiente, Gonzalo Núñez tomaba posesión de los bienes y tierras de doña Urraca.

Gonzalo Núñez de Aza era hijo de Diego Fernández de Aza, señor de Villamuza y de los heredamientos de Pastrana, y de doña Teresa Ramirez de Guzmán, y nieto de Fernán Alvarez de Aza, señor de Villada, Villamuza y otros lugares. Efectivamente, el 9 de octubre de 1395, Juana Núñez de Aza, hija de Fernán Alvarez de Aza y esposa de Gómez Gutiérrez de Ferrera, vendia a su sobrino Gonzalo Núñez todo lo que poseía en Villada y su término, «asi de casas fuertes e llanas, como de suelos poblados e por poblar, vasallos e tierras, desde la piedra del río fasta la hoja del monte", por la cantidad de 15.000 maravedís $(50)$. Unos meses antes de esta venta, el 1 de abril de 1395, Enrique III recibió la merced que de las tercias de Villada había hecho a Pedro Gutiérrez de Villapadierna y se las concedía a Gonzalo Núñez de Aza (51). De esta manera, toda Villada - salvo las dos partes que poseía el monasterio de Sahagún- pasó a pertenecer a Gonzalo Núñez de Aza.

Gonzalo Núñez no había tenido hijos de su mujer, Berenguela Cabeza de Vaca, pero si los tenía de una concubina llamada María Fernández de Villamuza. En 1399 Gonzalo Núñez consiguió que Enrique III legitimase a sus dos bastardos para que pudiesen heredar su patrimonio. Una vez conseguida la legitimación de sus hijos, Gonzalo Núñez otorgó su testamento. En él dejaba Villada y sus casas de Sahagún a su esposa Berenguela, que las poseería mientras viviese. Después deberian pasar a sus hijos Ramiro y Fernando, a quienes nombraba herederos universales, encargándole a su esposa que los mirase como a hijos y a éstos que la respetasen como a su madre (52). Nombraba albaceas a su esposa, a su cuñado el obispo de Cuenca, Juan Cabeza de Vaca, y a Diego Ramírez, obispo electo de León. Fundaba además una capellanía en Villada, a la que dotaba con los diezmos de Valdejoque, de la heredad de Pozuelos, de las que tenia en término de Grajera, y de parte de sus molinos. Pidió que se le diese sepultura en la iglesia de Santa María de la Hera de Sahagún, cerca del sepulcro de doña María, madre del maestre de Calatrava. Por último, ordenaba que se le diese la heredad de Tejadillos a Alvar Núñez de Aza, y algunos muebles y alhajas a Juan Ramírez de Palazuelos, Juan de 
Herrera y Juan de Valencia, sus criados, así como también 10 varas de paño a Marina González, 200 maravedís y 10 varas de paño a Elvira Alfón, esposa de Fernán González y 10 cargas de trigo en Villada a Teresa, cuñada de Alfonso Fernández de Valderrábano. Este testamento se otorgó en 1405, cuando Gonzalo Núñez ejercia las funciones de alcaide del castillo de Zorita. El 15 de diciembre de ese año, hallándose muy enfermo, otorgó un codicilo en la villa de Huete en el que ratificaba el testamento anterior y hacía una nueva donación a su esposa de las heredades que poseía en tierras de Guadalajara, Torres, Ciruelos e Hita (53). En ese codicilo dispone que lo hereden sus hijos, y si éstos fallecen sin herederos, que sus albaceas destinen sus bienes a la redención de cautivos. Finalmente, ordena que se den 20.000 maravedis a su sobrina Teresa, hija del comendador de Calatrava, para ayudar a su casamiento, y otros 10.000 maravedís a Beatriz, hija de Nuño Fernández Cabeza de Vaca.

Gonzalo Núñez falleció poco después de otorgar su último testamento y su viuda doña Berenguela y su cuñado el obispo de Cuenca aceptaron las disposiciones del donante el 12 de enero de 1406. Por su parte, Ramiro y Fernando, hijos de Gonzalo Núñez, denunciaron el testamento de su padre y, con la ayuda de su tío Diego Ramirez de Guzmán, arcediano de Valderas y obispo electo de León, pusieron pleito a su madrastra por la posesión de Villada (54). Mientras tanto, doña Berenguela Cabeza de Vaca había tomado posesión de los bienes que le pertenecian, como bienes gananciales durante su matrimonio. Ante el cariz que estaban tomando los acontecimientos, intervino el rey Enrique III que, por dos cédulas otorgadas en Valladolid el 8 de marzo y el 24 de abril de 1406 , prohibió a ambos hermanos que se abstuvieran de inquietar a doña Berenguela mientras no fuese oída en juicio (55).

Finalmente, ambas partes decidieron someter sus diferencias a dos compromisarios encargados de examinar la situación y de emitir un fallo. Así, Ramiro Daza, por su parte, y como tutor de su hermano Fernando, nombró compromisario a su tío Diego Ramírez de Guzmán, arcediano de Valderas (56). Doña Berenguela eligió a su hermano Nuño Fernández Cabeza de Vaca. El 29 de mayo de 1406, ambos compromisarios se reunieron en Villada y, una vez oídas las dos partes, determinaron que doña Berenguela disfrutase de la villa mientras viviese, según lo habia dispuesto su difunto esposo en su testamento (57).

La sentencia no satisfizo a los hermanos Daza, que volvieron a importunar a doña Berenguela por la posesión de Villada. El 7 de marzo de 1410 Fernando Daza dio poder a su hermano Ramiro para que de nuevo pleitease con doña Berenguela y ésta, por su parte, encargó a su segundo esposo, Alvar Rodríguez de Escobar, sobrino de su marido, que protegiese sus derechos sobre Villada (58). El pleito no prosperó y doña Berenguela siguió disfrutando de la villa.

Unos años más tarde, el 8 de marzo de 1423, doña Berenguela Cabeza de Vaca compró a Juana Ramírez, hija de Juan Ramirez de Palazuelo y viuda de Fernán Garcia de Lara, todo lo que ésta poseía en los términos de 
Villada, Grajera, Cisneros y Pozo de Urama, asi como la novena parte de los diezmos que le correspondían en la iglesia de San Juan de Grajera, por la cantidad de 1.000 maravedís (59).

La documentación del archivo de Osuna referida a Villada se interrumpe en ese año y no volvemos a tener noticias de los Aza y de doña Berenguela hasta el año 1436, en que Fernando de Aza vende la mitad de Villada al monasterio de Sahagún por 3.000 florines $(60)$. La venta no podria hacerse efectiva hasta el fallecimiento de doña Berenguela. Un año después Ramiro de Aza, hermano de don Fernando, regalaba la parte que poseia en Villada y en Grajera al mismo monasterio, para que los monjes rogasen a Dios por sus padres y por él mismo (61).

Sin embargo, ambas escrituras quedaron sin efecto cuando el 2 de marzo de 1437 doña Berenguela Cabeza de Vaca donaba la mitad de Villada a don Fadrique Enríquez, hijo del almirante de Castilla Alfonso Enríquez. El motivo de la donación consistia en que el almirante había prestado hacía más de treinta años la cantidad de 3.000 florines al esposo de doña Berenguela, Gonzalo Núñez, y éste no los había devuelto (62). Por tanto, Villada era el pago del préstamo de los Enríquez. Unos meses más tarde, el 19 de noviembre de 1437, don Fadrique Enríquez y doña Berenguela llegaban a un acuerdo por el cual esta señora vendía al primero Villada y Grajera por 32.000 maravedís, de a dos blancas el maravedí. De ellos, recibiría 12.000 maravedís en un juro de heredad situado sobre las alcabalas de la madera y fruta de Valladolid y los 20.000 restantes le serian pagados progresivamente en varios años (63). Poco después, doña Berenguela se dio por satisfecha de la venta y, de esta manera, pasó Villada a los dominios del almirante.

Pero los Enriquez sólo eran señores de la parte de Villada que había pertenecido a los Aza. Para poseer el señorío completo de la villa era necesario llegar a un acuerdo con su otro señor, el monasterio de Sahagún. El cenobio se negó a enajenar las dos partes que poseía en la villa de Villada. Entre los años 1438 y 1470, fueron muy frecuentes las diferencias y litigios dentro de Villada, entre los vasallos de los Enriquez y los del monasterio. La situación era insostenible y, por ello, en 1470 don Fadrique pidió al abad de Sahagún que le vendiese su parte. El monasterio, para evitarse conflictos continuos con los Enríquez, se decidió entonces a enajenar definitivamente las dos partes que tenia de la villa. Con este fin, solicitó del Pontífice el oportuno permiso y éste le llegó en forma de bula dada por Pío ll en Roma, el 8 de febrero de 1471 (64). De todas formas, hubo que esperar aún trece años más para que la compra se llevase a efecto.

El 29 de octubre de 1484 se llegó finalmente a una concordia con el monasterio de Sahagún. En ese año ya era señor de Villada don Enrique Enríquez, tercer hijo del almirante Fadrique, de quien había heredado la villa. Don Enrique, en la fecha ya señalada, compró al abad los ochenta vasallos y solares que le pertenecian en Villada, por la cantidad de 80.000 maravedís de juro de heredad, 65.000 en las alcabalas de Sahagún y 
15.000 en las de León (65). Los ochenta vasallos del monasterio vivian en la calle que llamaban de Sahagún y de cada vecino los monjes percibían 80 cargas de pan, 23 gallinas y 23 cornados de la moneda vieja. Se concertó también que el monasterio se quedase con dos casas, con su préstamo y heredades, para recoger los diezmos, las ofrendas y otras rentas. Los que en ellas viviesen como mayordomos o familiares del cenobio serian francos de servicios, empréstitos, sernas y huéspedes debidos al señor, pechando solamente con los tributos debidos al concejo. Finalmente, el monasterio pedia a Enrique Enríquez que no permitiese que los parroquianos del barrio de San Frutos se pasasen a vivir a la feligresia de Santa María, porque ello significaría la disminución de las rentas decimales que percibía el cenobio. Había que intentar, según esta petición, que al menos se mantuviesen en San Frutos los mismos feligreses que lo habitaban en el momento de la venta. El monasterio se reservaba, pues, los diezmos y el patronato de la iglesia de Villada.

A este respecto, es interesante conocer la situación de la villa de Villada en 1484, año en que se lleva a cabo la venta. El monasterio, a petición de don Enrique Enríquez, redactó una información sobre lo que poseía en Villada. Según este informe, el cenobio tenía en los arrabales que se hallaban fuera de la villa unos setenta vecinos y la mitad de veintiocho. Las rentas que le proporcionaban ascendían a 20.000 maravedis anuales (66). Diversos testigos afirmaron después que los 80.000 maravedís que había pagado don Enrique al monasterio venían a ser un tercio más de lo que valía todo lo que el cenobio poseía en la villa. De esta información se deduce además que en total eran ochenta y cuatro los vasallos de Sahagún en Villada, es decir, cuatro más de los que aparecen en el contrato de venta.

Así pues, tras esta compra, la villa de Villada pasaba a pertenecer por entero a don Enrique Enriquez.

\subsection{Villavicencio}

Este lugar, como Villada, era también de behetría. Según un informe del archivo de Osuna, pertenecia a los siguientes señores: el abad de Sahagún, Suer Téllez, García Díaz, Pero Rodríguez, Gómez Lazareno, Fernando Rodríguez, la abadesa doña María de Gradefes, Gonzalo Rodríguez Valera, Elvira Lazareno, Estebanía Lazareno, Aldara Ruiz, Pedro García, Marina García y Sancha Pérez (67).

No volvemos a tener noticias de este lugar hasta el 29 de enero de 1443, en que el concejo y los vecinos de Villavicencio se sometieron, bajo pacto de vasallaje, al almirante don Fadrique Enríquez entregándole la jurisdicción civil y criminal, como vasallos de behetría (68). Los vecinos de Villavicencio se obligaban a dar al almirante y a sus sucesores, en reconocimiento de señorio, 30 cargas anuales de pan - la mitad de trigo y la otra de cebada- 3.000 maravedís, un par de gallinas y un ánsar por cada 
vecino; las aves las entregarán por Navidad y los maravedís los pagarían por tercios anuales. El señor se compromete a guardarles sus fueros y a no entregar la villa a otro linaje. Finalmente, las monjas de Santa Clara de Valladolid, que eran señoras de una parte de la villa, renunciaron poco después a su dominio en favor de don Fadrique (69).

Sin embargo, unos años después, el concejo de Villavicencio denunció esta escritura de vasallaje, alegando que la villa era behetria de los descendientes de los primitivos señores y que, por tanto, la entrega a los Enríquez era nula (70). Y así, los vecinos de la villa pusieron pleito en la chancilleria de Valladolid a doña María de Luna, viuda de don Enrique Enríquez, a su hija Teresa y a su yerno el conde de Alba de Aliste. La villa pretendia dejar de ser señorio y pasar al realengo. La sentencia, dictada el 26 de febrero de 1507, fue favorable a la villa (71). El conde de Alba de Aliste recurrió contra ella, pero la sentencia de revista del 8 de junio de 1536 le fue también desfavorable. Unos años más tarde, el conde volvió de nuevo a protestar contra esta sentencia, pero aún no se había llegado a un acuerdo cuando los bienes del linaje Enriquez se integraron en el marquesado de Tábara.

\section{LA UNIFICACION DE LOS TRES MAYORAZGOS. EL MARQUESADO DE TABARA}

El 9 de septiembre de 1541 Carlos V, por un privilegio otorgado en Génova, concedía a don Bernardino Pimentel el título de marqués de Tábara (72). Don Bernardino había sucedido a su padre Pedro Pimentel en la posesión de los mayorazgos de los Pimentel y los Almansa y habia casado con Constanza Osorio Bazán, hija del conde de Lemos don Pedro Alvarez Osorio. Un año después, el 4 de marzo de 1542, don Bernardino aumentaba su patrimonio con la compra a Carlos $V$ de la villa de Villafáfila y sus lugares de San Agustín y Revellinos, situados en la encomienda de Castrotorafe (73). Villafáfila pertenecía a la Orden de Santiago y para enajenarla el monarca solicitó la oportuna bula pontificia. El precio pagado por Pimentel fue de 13.634.186 maravedís y en él se incluía la jurisdicción, el yantar, el portazgo, los mostrencos y las dos terceras partes de los diezmos del pan, vino y menudos de siete vecinos de la villa, después de que el obispo de Astorga escogiese otros diez diezmeros. La carta de pago fue otorgada en Valladolid por el tesorero del rey Alonso de Baeza, el 31 de marzo de ese mismo año. La venta de Villafáfila se inscribe en el proceso iniciado por Carlos $V$ en los años treinta del siglo XVI, de enajenación de tierras y lugares pertenecientes a las Ordenes Militares, con objeto de procurar ingresos a la hacienda real (74). Poco después, el 2 de junio de 1542, el marqués de Tábara y su esposa, con licencia de Carlos $V$ dada unos años antes, incluian en el mayorazgo fundado por su padre la villa de Villafáfila, las casas de Valladolid y sus muebles, los juros, 500 marcos de plata labrada y los derechos que poseía doña Constanza, como hija del conde de Lemos, a la villa de Ponferrada y a la mitad del lugar de Cabezón de Valderaduey. El heredero del mayorazgo sería su hijo 
Pedro, que llevaría el apellido y armas de los Pimentel-Osorio. Don Pedro, segundo marqués de Tábara, heredó también el mayorazgo de los Enríquez, al casar con la heredera de este último linaje, doña Terèsa Enríquez. Los tres mayorazgos se unieron, pues, a mediados del siglo XVI en una única persona, el marqués de Tábara.

El patrimonio de los marqueses de Tábara hacia mediados del siglo $X V I$ se hallaba formado por tres villas de cierta importancia, Villafáfila, Tábara y Villada, otras dos de menor entidad, Alija y Villavicencio, y una serie de lugares, tales como Ginestacio, Puente de Vizana, la mitad de Pobladura del Valle, Comonte, El Burgo y La Nora. Se trataba de un conjunto territorial disperso por las actuales provincias de Palencia, León y Zamora. Buena parte de los pueblos procedentes del linaje Pimentel se hallan situados en León, al noroeste de la villa zamorana de Benavente: Ginestacio, Alija del Infantado, La Nora y El Burgo y Puente de Vizana. En el norte de la actual provincia de Zamora se encontraban los territorios más importantes: Tábara y Villafáfila, con sus respectivas tierras. También estaban situadas en esta zona las otras localidades que habian pertenecido a los Pimentel, es decir, Pobladura del Valle y Comonte. Finalmente, Villada y Villavicencio de los Caballeros se hallan en la provincia de Palencia.

\section{INTERVENCION DE LOS MARQUESES EN LAS ALCABALAS DE SUS DOMINIOS}

Muy probablemente desde 1496, y con toda seguridad desde 1518, los marqueses retienen las alcabalas de sus dominios bajo un sistema de encabezamiento que aquí significa, esencialmente, la prórroga cada cuatro años de una cantidad fija. Esta cantidad asciende a 70.580 maravedís y se mantiene, al menos, hasta el año 1566 (75).

Esta vía de apropiación de las alcabalas difiere de la usada en algunos grandes Estados señoriales. De los escasos estudios sobre el régimen señorial en el siglo XVI se desprende que, al menos en buena parte de ellos, las alcabalas habían sido completamente enajenadas a los señores, ya fuera por una concesión real explícita o por una aceptación tácita de la monarquía (76). Por tanto, los titulares de estos señoríos no tenían el menor interés en que esta renta se convirtiera en una cantidad fija. En el marquesado de Tábara, en cambio, no existe una enajenación completa de ningún tipo. Esta diferencia y, en consecuencia, el que se adopte otro procedimiento, puede provenir de la formación tardia de este señorío y de su posición de segunda fila con respecto a los vinculados a las máa grandes familias del reino (77).

El mantener el encabezamiento de los 70.580 maravedis se presenta como una especie de merced real al marqués y a sus súbditos (78). Al mismo tiempo, tanto don Bernardino como posteriormente don Pedro Pimentel muestran un decidido interés en mantener cada cuatro años 
este encabezamiento y por los citados 70.580 maravedís. El motivo de este interés puede estar en el temor de estos señores de que cualquier variación en el cobro recibido por ellos desde principios de siglo pudiera suponer una merma de sus derechos consuetudinarios a las alcabalas y una reversión de éstas a la Corona (79). También cabe pensar que los marqueses prefirieran que no se incrementara esta renta para atraer así a su señorio un mayor número de vasallos. En cuanto al reparto de estos maravedis en las distintas villas y lugares, sólo tenemos datos parciales y para 1529. En aquel año, las alcabalas de Tábara, Alija y sus tierras respectivas ascendian a 28.420 maravedis (80).

En ocasiones, la percepción de alcabalas sirvió también para que la apropiación se extendiera al conjunto de las rentas reales. La mejor prueba de esto es la merced de la reina doña Juana, el 10 de febrero de 1513, a doña Inés Enríquez, viuda de don Pedro Pimentel. En ella se conceden "las alcaualas e terçias e moneda forera e seruiçio e medio seruiçio e cabeça de pecho" de la villa de Tábara y su tiẹrra y se especifica que la causa de esta merced es una petición previa de doña Inés, en donde exponía que ella había percibido estas rentas en los años anteriores y hasta $1512(81)$.

\section{INGRESOS Y BIENES DE LOS SEÑORES DE TABARA EN SUS VILLAS $Y$ LUGARES}

\subsection{Tábara}

Hacia 1541, los lugares poblados que formaban parte de la comarca de esta villa eran los siguientes: Abejeras, Ferreras de Arriba y Ferreras de Abajo, Ferreruela, Escober, Litos, Moreruela, Riofrío de Aliste, Sesnandez, San Martín, Faramontanos, San Lorenzo, Santa Eulalia y Pozuelo. Otros dos lugares se hallaban despoblados: Orejón y Moratones (82). EI 26 de abril de 1471, el concejo de Tábara había llegado a un acuerdo con don Pedro Pimentel según el cual los vecinos de la villa deberían pagar anualmente al señor, en reconocimiento de vasallaje, lo siguiente: 54 libras de queso, un carnero, 24 perdices y 500 maravedís por usar los montes de la villa. Además, los lugares de Escober y Sesnandez entregaban 294 maravedis y cada una de las aldeas un carnero (83).

A juzgar por lo que ocurría en Ferreruela y Abejeras, se arrendaban a los concejos los términos de cada lugar. El arrendamiento de Ferreruela es de 1510 y se realiza bajo el mandato de doña Inés Enríquez, viuda de don Pedro Pimentel. El concejo lleva en arriendo los terrenos yermos, montes, prados, pastos y aguas desde esta población a la de Tábara. A cambio, entregará 70 maravedís de la moneda usual y un carnero y media carga de cebada por cada vecino (84). En cuanto al aforamiento de Abejeras de 1541 , constituye una especie de renovación del efectuado anteriormente con doña Inés. Por las tierras, montes, prados y pastos del lugar 
recibirá don Bernardino 60 ducados de a 375 maravedís, y un carnero viejo, 50 libras de queso y 24 perdices de cada vecino. Todo esto tenía que ser pagado y entregado en la villa de Tábara (85).

Además de las alcabalas, los marqueses percibian los diezmos de Tábara y de sus lugares poblados. Poseían tres dehesas -en Carvajosa, Quintos y Misleo-, dos huertas, tres molinos - uno en Tábara, otro en Orcejón y otro en Riofrío-, varias tierras, la barca de Misleo, y la pesca del río Esla, también en Misleo, que se arrendaba (86).

\subsection{Villafáfila}

Por las rentas que la mesa maestral y la encomienda de Castrotorafe tenían anteriormente en Villafáfila y sus lugares de San Agustín y Revellinos se pueden conocer, aproximadamente, las que percibían los marqueses. En la década de 1530 estas rentas comprendian la de las heredades, viñas y casas de la encomienda, la de los siete diezmeros de la encomienda, la de la escribanía, el portazgo, la cabaña de hacer sal, el yantar, la martiniega de los vecinos de Villafáfila y su jurisdicción, las penas de cámara, los mostrencos y las rentas de la mesa maestral. De todas ellas, hay constancia de que se arrendaban o aforaban las heredades, viñas y casas. También se daban en arriendo los siete diezmeros, la escribania, el portazgo y la cabaña de hacer la sal. Además, la Orden de Santiago poseía allí dos silos, que en 1536 almacenaban una fanega de trigo (87).

Casi inmediatamente después de la toma de posesión de Villafáfila, el mismo año de 1542, se registran las primeras compras de casas en la plaza de la villa. El vendedor es el sexto conde de Benavente, don Antonio Alfonso Pimentel (88), y quizá se trate de las mismas casas que don Pedro Pimentel había comprado a unos particulares en $1475(89)$ y posteriormente vendido a su hermano, el cuarto conde de Benavente (90). La política de adquisición de casas y suelos de casas en Villafáfila continúa, al menos, hasta 1556 (91).

Villafáfila y su tierra ofrecen, además, el interés de ser los únicos núcleos en donde poseemos alguna estimación de su habitantes en estos años inmediatamente posteriores a la incorporación al marquesado. Con todo, estos datos son muy poco precisos. Están contenidos en la sentencia de un pleito de 1550 , donde se especifica que sla dicha uilla de Villafáfila hera pueblo muy grande y en ella y su tierra auia más de seiscientos vezinos" (92).

\subsection{Villada}

En esta villa sólo sabemos que los marqueses de Tábara poseían un molino, cercano al río Valderaduey, y la huerta grande de la villa (93). Cobraban las alcabalas, las penas de cámara y los diezmos de algunos lugares. A finales del siglo XV el señor arrendó al concejo de Villada el 
término espoblado de Villamuza, con la condición de que pagase al año 453 fanegas y 4 celemines de trigo (94).

\subsection{Villavicencio}

Los vasallos de esta villa pagaban humazga al señor, pero apenas si sabemos algo más, salvo que los Enríquez-Pimentel poseían en ella una casa fuerte, un molino y otras varias heredades.

\subsection{Alija}

Lógicamente, pasaron a los marqueses las posesiones que los $\mathrm{Pi}-$ mentel tenían anteriormente en la villa. En el período comprendido entre 1446 y 1448 estas posesiones consistian en una casa "de cal e canto con dos torres e otras casas que están dentro", una casa situada fuera del castillo y que se destinaba a panera y una huerta en las proximidades del castillo, con perales y otros árboles frutales. Por otra parte, los Pimentel eran propietarios de ocho yugadas de tierra de pan, que habian sido arrendadas en contratos forales a los campesinos de la villa, los cuales pagaban al señor en especie (95).

A lo largo del siglo XVI y, más concretamente, entre 1537 y 1557 , se advierte un decidido interés de los marqueses por adquirir huertas en la villa $y$, secundariamente, olmares, prados y casas. De cuatro trueques y cinco compras efectuadas en esos años, tres trueques corresponden a huertas - dos en Alija y otra en su aldea de El Burgo- y otro a tierras de labor (96). Las cinco compras se refieren, en un caso, a una huerta y un olmar en Alija (97), en otras dos ocasiones, a un olmar y a otro pedazo de olmar unido a un prado (98), y otras dos adquisiciones corresponden a casas (99). En cuanto a los bienes objeto de cambio, se trata de tres tierras de labor y un linar por las tres huertas, y otra tierra de labor por las dos tierras aportadas por dos vecinos de Alija.

\subsection{Ginestacio}

De esta localidad sólo sabemos que en 1448, y durante el señorío del conde de Benavente, aportaba 200 maravedís de yantar y 72 cargas anuales por ciertas localidades de los Pimentel. En ese mismo año, sus señores tenían también treinta y dos foros sobre veintinueve casas y tres huertas, que les proporcionaban al año ochenta y nueve maravedís, quince dineros y cincuenta y cuatro gallinas (100).

\subsection{Puente de Vizana}

Los Pimentel-Enríquez tenían en este lugar doce cargas de pan, mediado trigo y cebada, que había comprado doña Inés Enríquez el 15 de 
marzo de 1504 (101). Como señores del lugar, poseian el derecho eminente sobre todo su término y ello les permite realizar en 1516 un aforamiento perpetuo con el concejo de Comonte por el aprovechamiento del agua de los molinos. El concejo y los vecinos, que estaban interesados en el riego de sus linares y heredades, se comprometen a pagar veinte cargas de pan anuales (102).

También poseían los marqueses en Puente de Vizana el derecho de patronato y presentación del beneficio de la iglesia de Nuestra Señora y los diezmos del lugar. El patronato y presentación se obtuvo por una donación de Inés Vaca, el 26 de abril de 1557, en atención a las mercedes que había recibido del marqués (103). Esta misma señora y Alvaro Garabito, vecinos de León, venden el 12 de noviembre del mismo año los diezmos de Vizana por una cantidad de 313 ducados (104).

\subsection{Pobladura del Valle}

El señorio de este lugar estaba compartido por los marqueses de Tábara y Villafranca. Dentro de los derechos del de Tábara estaba la presentación de la iglesia de Santo Tomás, que adquirió el 1 de junio de 1541 (105).

\section{RELACIONES ENTRE LOS MARQUESES Y SUS VASALLOS}

No hay constancia de ninguna resistencia de las distintas villas y lugares a entrar en el señorío. Probablemente esto se deba a que todas ellas habian pertenecido anteriormente a distintos dominios y no había ningún cambio esencial entre la forma de usar el marqués sus derechos jurisdiccionales y sus antiguos dueños.

La úníca protesta conservada ante algunas medidas de gobierno se registra en Villafáfila, que había formado parte de la Encomienda de Castrotorafe, dentro de la Orden Militar de Santiago. Está recogida en una ejecutoria de la Chancilleria de Valladolid, del 12 de diciembre de 1550, en el pleito entre don Bernardino Pimentel y el concejo y vecinos de Villafáfila. Se inicia con una demanda del concejo del 15 de junio de 1543 y con la respuesta del procurador de don Bernardino ante sus argumentos (106).

De los alegatos del procurador del concejo se desprende que la Orden de Santiago, quizá por tener unos dominios muy amplios y dispersos, no había ejercido una fuerte presión señorial sobre la villa, en contraste con la actuación posterior de don Bernardino. Concretamente, se compara su actitud en cuanto al hospedaje y a las funciones del teniente de alcalde mayor. La Orden de Santiago, dice, nunca había puesto huéspedes a los vecinos y, en cambio, cuando don Bernardino compró la villa, les impuso esta obligación. Igualmente, en la época anterior, los tenientes que sustituian a los alcaldes mayores no intervenían en causas de primera instan- 
cia, y ahora ejercen esta jurisdicción con los alcalces ordinarios. Por tanto, aqui se identifica la costumbre con las formas de gobierno del señorío anterior.

Las otras quejas tienen como causa disposiciones del marqués consideradas también por los vecinos como un ataque a la autonomía del gobierno concejil, a las ordenanzas de la villa o a los usos consuetudinarios. Se refieren a la veda de la caza y a las penas impuestas a quienes la rompieran - mientras que antes se cazaba libremente- a plantar más árboles en los prados concejiles de lo que indican las ordenanzas, y a la intervención en los nombramientos concejiles. Esta intervención supone un cambio con respecto a épocas anteriores, en las que se celebraban las elecciones sin necesidad de la presencia de los agentes señoriales ni de la confirmación posterior. El marqués impone la presencia del alcalde mayor en la elección de alcaldes, regidores y procurador. El nombramiento final es obra de don Bernardino, que utiliza un sistema también empleado en otros señorios (107): Se presenta al noble dos nombres por cada uno de los cargos, para que apruebe al conjunto de los candidatos y después elija entre ellos. Por último, protestan de que el marqués provea a Villafáfila de escribano y de un mayordomo del concejo para las finanzas y gastos. En este segundo tema, lo habitual era un procurador, nombrado por las autoridades concejiles para encargarse de la hacienda local.

Frente al derecho consuetudinario, don Bernardino esgrime el derecho señorial. Según la exposición de su representante, en sus atribuciones entra el nombramiento de cargos del concejo, de la escribania y el derecho de hospedaje, independientemente de que los anteriores señores lo hayan puesto en práctica o no. La insistencia en estas cuestiones por las dos partes hace pensar que en ellas radicaban los puntos centrales del conflicto.

La sentencia limita a doce los días de posada que puede exigir a los vecinos el señor, remite a las ordenanzas de la villa sobre el número de árboles puestos por particulares en los prados concejiles, suprime la veda de la caza y da plena satisfacción a la villa en la elección de sus autoridades. En adelante, el señor no podrá poner mayordomo ni intervenir, directa o indirectamente, para elegir alcaldes, regidores y procurador. Además, el concejo podrá nombrar un escribano para sus asuntos específicos. Sin embargo, no se admite la queja sobre la actividad del teniente del alcalde mayor.

Podríamos pensar que esta sentencia fue, en lo esencial, una victoria para Villafáfila y su tierra. Pero no sólo protesta contra ella el marqués por lo que considera un importante recorte de sus derechos. También el concejo piensa que no han sido suficientemente atendidas sus peticiones en el tema de las posadas e intenta reducir más su número. Con todo, la sentencia se confirma a pesar de lo alegado por ambas partes.

Dada la insistencia señorial en poner cargos concejiles, podríamos suponer que los Pimentel-Enríquez usaban en otras villas el mismo sistema de nombramiento que en Villáfáfila. Sin embargo, la falta de docu- 
mentación impide pronunciarse sobre lo ocurrido en esta materia durante los primeros años del marquesado.

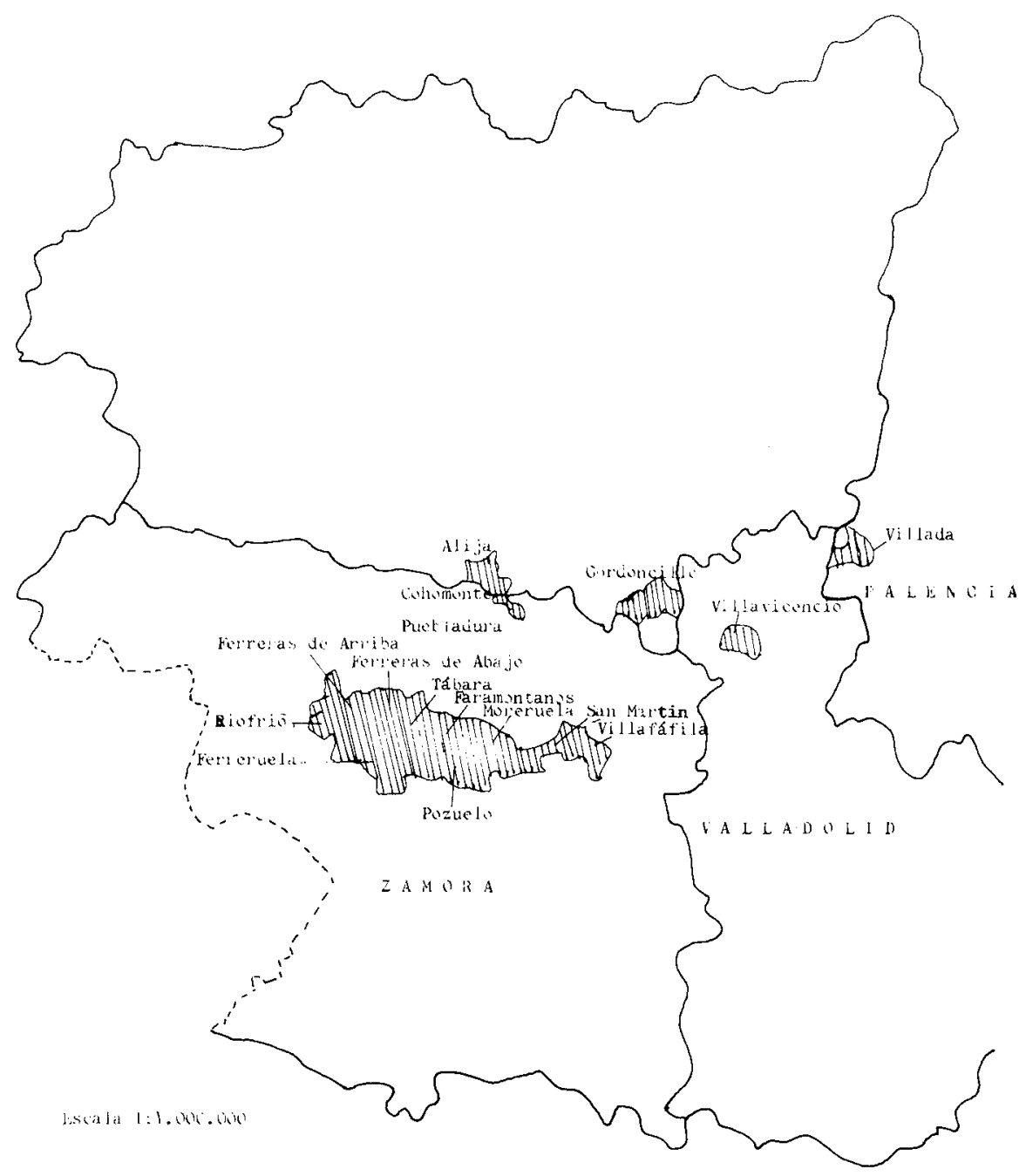

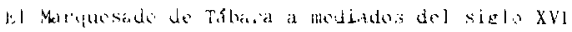




\section{NOTAS}

(1) Sobre los señoríos de los Mendoza tratan dos recientes trabajos de A. Franco Silva: “El adelantado de Cazorla Don Pedro Hurtado de Mendoza. Formación de sus señoríos en tierras de Guadalajara", en Gades, 11, en prensa; y "La herencia patrimonial del Gran Cardenal de España Don Pedro González de Mendoza», en Historia, Instituciones, Documentos, 9 (1982), pp. 453-491.

(2) La mejor muestra de los esfuerzos de los condes de Benavente para recuperar sus antiguos territorios nos la proporciona la demanda de don Alonso Pimentel, $5 .^{\circ}$ conde de Benavente, para solicitar la restitución de Pobladura del Valle, Comonte, Gordoncillo y Retuerta. El principal argumento de esta demanda es que estas localidades están incluidas en el mayorazgo formado por el $2 .^{\circ}$ conde de Benavente y, por tanto, son bienes inalienables de la Casa. Es un documento sin fecha, aunque se puede suponer de los últimos meses de 14990 de los primeros meses de 1500, dado el momento en que don Alonso sucede en el condado a su padre y la reclamación de Gordoncillo y Retuerta. Archivo Histórico Nacional (en adelante, AHN). Sección Osuna. Leg. 482, N. ${ }^{\circ} 35$. Sobre los pleitos, mucho más tardios, entre los marqueses de Tábara y los Almirantes de Castilla en relación con Villada y Villavicencio hay referencias en AHN. Osuna. Leg. 2176, N. ${ }^{\circ} 6$ y N. ${ }^{\circ} 7$, Leg. 2291, N. 13 y Leg. $2161, N .^{\circ} 1$.

(3) AHN. Osuna, Leg. 516, N. ${ }^{\circ} 5^{28}$.

(4) AHN. Osuna, Leg. $482, N^{\circ} 3^{25}$.

(5) AHN. Osuna, Leg. 3329.

(6) Archivo de los condes de Luna. Papel, N. ${ }^{\circ} 138$. Esta dote ha sido tratada brevemente por C. ALVAREZ ALVAREZ en El condado de Luna en la Baja Edad Media, León, 1982, p. 136.

(7) 23 de abril de 1446. AHN. Osuna, Leg. 482, N. ${ }^{\circ} 2^{2}$. La relación de esta merced con las circunstancias políticas ha sido analizada por I. BECEIRO PITA en su tesis doctoral inédita sobre los señores de Benavente y su estado señorial: El condado de Benavente en el siglo XV. Valladolid, 1980, t. I, p. 159.

(8) 17 de mayo de 1469. AHN. Osuna, Leg. 2148, N. $^{\circ} 3$.

(9) Las noticias de este trueque están contenidas en el memorial de la demanda puesta por Maria Pacheco a su hijo don Alonso Pimentel, $5 .^{\circ}$ conde de Benavente, sobre la posesión de la mitad de Gordoncillo. AHN. Osuna, Leg. 482, N. ${ }^{\circ} 37$, sin fecha.

(10) Archivo de los condes de Luna. Papel, N. ${ }^{\circ} 138$. Los acuerdos entre los condes de Luna y Benavente, previos a esta dote, están recogidos en AHN. Osuna, Leg. 482, N. ${ }^{\circ}$.

(11) C. ALVAREZ ALVAREZ, El condado de Luna..., p. 142.

(12) AHN. Osuna, Leg. 3329.

(13) AHN. Osuna, Carp. 60, N. ${ }^{\circ} 7$.

(14) La explicación del motivo de la venta está contenida implícitamente en la licencia dada para ella por María de Vega, el 28 de mayo de 1434. AHN. Osuna, Leg. 482, N. 2.

(15) Real Academia de la Historia. Colección Salazar. M-21, fols. 259-263.

(16) 19 de enero de 1484. AHN. Osuna, Leg. 482, N. ${ }^{\circ}$.

(17) AHN. Osuna, Leg. $482, N^{\circ} 35$ y N. ${ }^{\circ} 37$.

(18) AHN. Osuna, Leg. 483, N. ${ }^{\circ} 2^{\circ}$

(19) AHN. Osuna, Leg. 3329. Cebrones del Río, en León, pertenecia a los Benavides desde el año 1435, en el que Fernán González Portocarrero lo concedió a Juan Alfonso de Benavides. 
M. C. QUINTANILLA RASO, «Aportación al estudio de la nobleza en la Edad Media: la Casa Señorial de Benavides», en Historia, Instituciones, Documentos, 1 (1974), p. 183.

(20) Todas las escrituras concernientes a la venta de Cebrones del Río y Pobladura del Valie se encuentran en AHN. Osuna, Leg. 482, N. ${ }^{\circ}$ 2. Del traspaso de estas dos localidades se hace eco M. C. QUINTANILLA RASO en "La Casa Señorial de Benavides en Andalucia», en Historia, Instituciones, Documentos, 3 (1976), p. 445.

(21) AHN. Osuna, Leg. 3329.

(22) AHN. Osuna, Leg. 2142, N. ${ }^{\circ} 1$.

(23) I. BECEIRO PITA, El condado de Benavente..., p. 159.

(24) AHN. Osuna, Leg. 4210, N. ${ }^{\circ} 2$.

(25) AHN. Osuna, Leg. 2223, N. ${ }^{\circ} 3^{\prime}$. La villa de Tábara habia pertenecido a la Orden del Temple hasta su extinción, en que pasó a la Corona.

(26) AHN. Osuna, Leg. 3329.

(27) Ibidem.

(28) Ibidem.

(29) Ibidem.

(30) Ibidem.

(31) AHN. Osuna, Leg. 3329.

(32) Ibidem y Leg. 482.

(33) AHN. Osuna, Leg. 3329.

(34) AHN. Osuna, Leg. 3921.

(35) En este año, las rentas de Almanza están englobadas en el conjunto de las de la Casa de Benavente $y$, a través de pujas sucesivas, las alcabalas fueron arrendadas en 140.000 maravedis y por cuatro años. AHN. Osuna, Leg. 417, N. ${ }^{\circ} 34^{28}$. Por su parte, don Pedro Pimentel recibe de su hermano el conde 17.600 maravedis "de la renta de la encomienda de Villafáfila deste dicho año". AHN. Osuna, Leg. $417, \mathrm{~N}^{\circ} 33^{\circ}$.

(36) En las cuentas del tesorero del condado de Benavente, en 1499, se dice: “De las rentas de Villafáfila no se le carga cosa ninguna porque se dio por ninguno el arrendamiento y las leuó el comendador, entiéndese de las rentas de la encomienda". Con todo, el señor de Benavente recibe este año las alcabalas de Villafáfila. AHN. Osuna, Leg. $418, N^{\circ} 1^{s}$.

(37) AHN. Osuna, Leg. 3329.

(38) Don Fadrique era hijo del almirante Alonso Enríquez y de su mujer Juana de Mendoza. Ambos esposos formaron un mayorazgo en Toro el 19 de abril de 1426 en virtud de una licencia real dada por Juan II el 15 de abril de ese año. El mayorazgo principal lo heredaria su hijo Fadrique, que obtendría Mediana de Rioseco, Aguilar de Campos, Arcos de la Frontera, las tierras de Lopera y Gorgonza, las aceñas cercanas a la villa de Torrelobatón, esta villa de Torrelobatón, con su alcázar y heredades, las villas de Támariz, Villabrágima — con La Puebla-, Moral, Villalabre, Berralcete, Bustillo, Villanueva, Escobar, Villacreces, las casas y heredades que tenian en Sahagún y su término, las casas de Medina del Campo y de San Román, las viñas, vasallos y heredades que tenian en Becilla, las casas mayores que tenian en Valladolid y los bienes que tenian en esa villa, así como todas sus posesiones de León y Valencia de don Juan, la mitad de las jabonerías de Sevilla y 30.000 maravedis de los 70.000 que tenía de juro de heredad en las juderias de Córdoba. Don Enrique Enríquez, segundo hijo del almirante, heredaba un mayorazgo formado por las villas de Bolaños, Villafurciente y los vasallos de Valdunquillo, con sus heredades, la villa de Belber, las salinas de Villafáfila, Viveros y Villacreces, las casas de Zamora que compraron a Juan Hernández de Toledo, todo lo que les pertenecian en las aceñas que fueron de Diego López de Zamora, en término de Piedrahita, la heredad de Pajares, que compraron a Pedro Alfonso de Escalante, 30 lanzas y 30.000 maravedis de juro que el almirante gozaba en las juderías de Córdoba. AHN. Osuna, Leg. 3329. Véase a este respecto Pascual Martínez Sopena, El Estado señorial de Medina de Rioseco bajo el almirante Alfonso Enriquez (1389-1430), Valladolid, 1977.

(39) AHN. Osuna, Leg. 3329.

(40) AHN. Osuna, Leg. 3329.

(41) Ibidem.

(42) Ibidem.

(43) Ibidem.

(44) Ibidem.

(45) G. MARTINEZ DIEZ, Libro Becerro de las Behetrias. Estudio y texto critico, t. 1, León, 1981, p. 349.

(46) AHN. Osuna, Leg. 3329.

(47) Ibidem. 
(48) Ibidem.

(49) AHN. Osuna, Leg. $2160, N^{\circ} 3^{1}-^{3}$.

(50) AHN. Osuna, Leg. 2160, N. ${ }^{\circ} 4$.

(51) AHN. Osuna, Leg. 2168, N. ${ }^{\circ} 1^{1.2}$.

(52) AHN. Osuna, Leg. 2160.

(53) Ibidem.

(54) AHN. Osuna, Leg. $2160, N .^{0} 7$.

(55) AHN. Osuna, Leg. $2160, N^{\circ} 8^{1}{ }_{-} 2$.

(56) AHN. Osuna, Leg. 2160, números 8 y 9.

(57) Ibidem.

(58) AHN. Osuna, Leg. 2160, N..$^{\circ} 10$.

(59) AHN. Osuna, Leg. 2167, N.॰1.

(60) AHN. Osuna, Leg. 2160.

(61) Ibidem.

(62) AHN. Osuna, Leg. 2160, N.o 12.

(63) Ibidem.

(64) AHN. Osuna, Legs. 2160 y 2162.

(65) Ibidem.

(66) AHN. Osuna, Leg. 2162.

(67) AHN. Osuna, Leg. 3329.

(68) Ibidem.

(69) Ibidem.

(70) Ibidem.

(71) Ibidem.

(72) AHN. Osuna, Leg. $2121, N^{\circ} 2$.

(73) AHN. Osuna, Leg. 2152, N. ${ }^{\circ} 4^{\prime}$.

(74) Este es el mismo caso de Pastrana y Estremera, que serán analizadas por A. Franco Silva en un próximo trabajo.

(75) AHN. Osuna, Leg. 2125, $\mathrm{N}^{\circ} 1^{1}$ a $1^{30}$. Cédulas sobre las alcabalas del marquesado. El primer documento, del 14 de julio de 1496, está muy deteriorado. Esto impide poder comprobar aquí la intervención nobiliar.

(76) Véase a este respecto A. M. GUILARTE, El régimen señorial en el siglo XVI, Madrid, 1962, pp. 152-155.

(77) Agradecemos al profesor Bartolomé Yun sus observaciones sobre las alcabalas en algunos Estados señoriales del siglo XVI.

(78) El 30 de mayo de 1529, Carlos I manda a sus contadores mayores que no introduzcan ningún cambio en las alcabalas de Alija, Comonte, Ginestacio, La Nora, Pobladura del Valle, Tábara y su tierra, sino que le sigan dando a don Bernardino el encabezamiento por el precio de 70.580 maravedis, como lo habia tenido los años pasados. El 9 de julio del mismo año, el rey se dirige a los concejos de estas villas y lugares para que no acepten un nuevo encabezamiento más alto. AHN. Osuna, Leg. 2125, N. ${ }^{\circ} 14$ y N. ${ }^{\circ} 15-b$.

(79) A propósito de un pleito entre don Bernardino Pimentel y los contadores mayores sobre las aicabalas de Pobladura del Valle en los años anteriores, una cédula de Carlos I, del 19 de julio de 1517, especifica que "paresçio el dicho don Bernaldino estar en costumbre de rresçebir enteramente las dichas alcavalas del dicho lugar de Pobladura del Valle». AHN. Osuna, Leg. $2125, N .^{\circ} 1^{s}$.

(80) AHN. Osuna, Leg. $2125, N^{0} 1^{22}$.

(81) AHN. Osuna, Leg. 2125, N. ${ }^{\circ} 1^{13}$.

(82) AHN. Osuna, Leg. 3329.

(83) Ibidem.

(84) AHN. Osuna, Leg. $2129, N{ }^{\circ} 5$. Sólo se conserva la carpetilla.

(85) AHN. Osuna, Leg. $2129, N^{\circ}{ }^{\circ} 6$. Sólo se conserva la carpetilla.

(86) AHN. Osuna, Leg. 3329.

(87) AHN. Osuna, Leg. 2152, N. ${ }^{\circ}$. Averiguación de las rentas y vasallos que la mesa maestral y encomienda de Castrotorafe tenian en Villafáfila, San Agustín y Revellinos, todo lo cual se vendió a don Bernardino Pimentel, marqués de Tábara.

(88) 31 de julio de 1542. AHN. Osuna, Leg. 2152, N. ${ }^{\circ} 18$.

(89) 1 de enero de 1475. AHN. Osuna, Leg. 2152, $N^{\circ}{ }^{\circ} 15^{1}{ }^{2}$.

(90) AHN. Osuna Leg. $453, N^{\circ} 2^{1}$.

(91) 21 de octubre de 1566. AHN. Osuna, Leg. $2154, N^{\circ} 4$.

(92) AHN. Osuna, Leg. 2153, N. ${ }^{\circ} 4$. 
(93) AHN. Osuna, Leg. 3329.

(94) Ibidem.

(95) AHN. Osuna, Leg. 444. Libro de rentas del condado de Benavente entre 1446 y 1448.

(96) 16 de marzo de 1537. Trueque entre Juan de Rivera, contador de don Bernardino Pimentel, en nombre de éste, y Juan de Morán, vecino de Alija. Este último cede al marqués una huerta en Alija a cambio de dos tierras, una de cinco heminas de pan de sembradura y otra de dos heminas. AHN. Osuna, Leg. $2143, \mathbf{N} .^{\circ} 1$. Sólo se conserva la carpetilla.

18 de nero de 1557 . Trueque entre Felipe Alvarez, en nombre del marqués, y varios vecinos de Alija. Estos ceden al señor una huerta y un canto de casa en el término de El Burgo, aidea de Alija, por una tierra linar, de siete heminas de sembradura, y dos ducados. AHN. Osuna, Leg. 2143, N. ${ }^{\circ} 4$. Sólo se conserva la carpetilla.

8 de enero de 1557. Trueque entre el mismo Felipe Alvarez, en nombre del marqués, y otros varios vecinos de Alija. El marqués cede una tierra, que da media carga de pan de sembradura, y los vecinos una huerta, que proporciona cuatro heminas de sembradura. AHN. Osuna, Leg. $2143, N .^{\circ} 4$. Sólo se conserva la carpetilla.

De esta última fecha se conserva otro trueque en el que cambia el marqués una tierra de pan llevar por dos tierras de dos vecinos. AHN. Osuna, Leg. 2147, N. ${ }^{\circ} 4$. Sólo se conserva la carpetilla.

(97) 25 de septiembre de 1557. AHN. Osuna, Leg. 2143, N. ${ }^{\circ} 10$.

(98) 20 de abril de 1557 y 14 de mayo de 1557 . AHN. Osuna, Leg. $2143, N .^{\circ} 8$ y N. ${ }^{\circ} 9$, respectivamente.

(99) 25 de marzo de 1549 y 4 de septiembre de 1556 . AHN. Osuna, Leg. 2147, N. 3 . Sólo se conserva la carpetilla.

(100) AHN. Osuna, Leg. 444.

(101) AHN. Osuna, Leg. 2148, N. ${ }^{\circ} 4$. Sólo se conserva la carpetilla.

(102) 3 de marzo de 1516. AHN. Osuna, Leg. $2147, N^{\circ} 1$. Sólo se conserva la carpetilla.

(103) AHN. Osuna, Leg. $2148, N{ }^{\circ} 1$.

(104) lbidem.

(105) AHN. Osuna, Leg. $2150, N .^{\circ} 1^{1}$.

(106) 12 de diciembre de 1550 . Ejecutoria de la Chancilleria de Valladolid en el pleito entre don Bernardino Pimentel, marqués de Tábara, y el concejo y vecinos de Villafáfila. AHN. Osuna, Leg. $2153, N^{\circ} 4$.

(107) A. M. GUILARTE, El régimen señorial..., p. 93. 